\title{
Responses of rhizome length and ramet production to resource availability in the clonal sedge Scirpus olneyi A. Gray
}

\author{
Makihiko Ikegami · Dennis F. Whigham • \\ Marinus J. A. Werger
}

Received: 10 October 2005/ Accepted: 19 June 2006/Published online: 27 December 2006

(C) Springer Science + Business Media B.V. 2006

\begin{abstract}
The clonal plant Scirpus olneyi has two types of ramets within one clone; a ramet with a very long rhizome (LRR) and a ramet with a very short rhizome (SRR). Based on foraging theory of clonal plants, we hypothesised that these two types of ramets were functionally specialised to different tasks: the task of LRRs is for exploring while SRRs is for consolidating the patches. We also hypothesised that LRRs tended to produce LRRs continuously during a growing season to reach further patches while SRRs tended to produce SRRs fewer times to stay in the same patches. To evaluate these hypotheses, we analysed the sequence of two ramets of plants growing in
\end{abstract}

M. Ikegami · M. J. A. Werger

Department of Plant Ecology, Utrecht University, P.O. Box 80084, TB 3508 Utrecht, The Netherlands

D. F. Whigham · M. Ikegami

Plant Ecology Lab, SERC, P.O. Box 28, 647 Contees

Wharf Road Edgewater, 21037 Maryland, USA

D. F. Whigham

Department of Landscape Ecology, Utrecht University, P.O. Box 80084, TB 3508 Utrecht, The Netherlands

Present Address:

M. Ikegami ( $\square)$

Forest Research, Alice Holt Lodge, Wrecclesham,

Farnham, Surrey GU10 4LH, UK

e-mail: makihiko.ikegami@forestry.gsi.gov.uk four communities in the field and five treatments in garden experiments.

In the garden experiments, plants in high quality treatments (e.g. low salinity, full sun, and sufficient nutrient) produced proportionally more SRRs and branched more frequently than plants in low quality treatments (e.g. strong salinity or less light or less nutrient). LRRs kept producing LRRs in every treatment, but LRRs in low quality treatments produced less SRRs than LRRs in high quality treatments did. The field observations showed LRRs kept producing LRRs in every community in the same growing season, but SRRs production varied among communities. In the communities with larger biomass and high SRR ratio, LRRs produced more SRRs and those SRRs produced proportionally more SRRs. On the other hand, in the communities with smaller biomass and low SRR ratio, LRRs produced less SRRs and those SRRs produced proportionally less SRRs.The results of garden experiments and field observations support our hypotheses. Two ramets are functionally specialised to perform different tasks. And their production patterns are suitable to perform their tasks. And their production patterns are suitable to perform their tasks: the sequential production of LRRs allows plants to have higher chance to reach new locations, and the limited but sequential production of SRRs allows plants to consolidate the patches. The observed production patterns of two ramets 
are associated with phalanx and guerrilla strategies by Lovett Doust, and $S$. olneyi shows both strategies within relatively small scale environments.

Keywords Architecture $\cdot$ Clonal plant $\cdot$ Foraging . Life history strategy $\cdot$ Scirpus olneyi

\section{Introduction}

Clonal growth is one of the most successful propagation strategies in the plant world. By repeatedly producing genetically identical ramets, clonal plants develop a variety of architectural forms. The complexities of clonal architectures differ among plant species or within the same species growing in different environments (Bell 1980; Lovett Doust 1981; Bell 1984; de Kroon and Knops 1990; Hutchings and de Kroon 1994), thus these differences in ramet architectures may represent differences in foraging strategies of clonal plants (Lovett Doust 1981; Harper 1985; de Kroon and Knops 1990; Hutchings and de Kroon 1994; Dong 1996). Since plasticity in clonal architectures may be an adaptive plant trait in an evolutionary context (Hartnett and Bazzaz 1983), many studies have been made on clonal architectures of clonal plants (Bell 1980; Lovett Doust 1981; Bell 1984; de Kroon and Knops 1990; Hutchings and de Kroon 1994).

The clonal architectures can be adjusted by four elements; length of spacer, the branching frequency, branching angle and the sequence of ramets. The ability to produce spacers of variable length enables plants to escape from less favourable patches where resource levels are low or where competitive stress is high, or to consolidate or maintain favourable patches (Slade and Hutchings 1987a-c; Dong and de Kroon 1994; de Kroon and Hutchings 1995; Dong 1996). The ability to increase branching frequency allows plants to occupy patches with favourable environments (Slade and Hutchings 1987a-c; Dong and de Kroon 1994; de Kroon and Hutchings 1995; Dong 1996). One typical example of the relationship between clonal architectures and environments is the phalanx and guerrilla strategy (Lovett Doust 1981).

Clonal plants with the phalanx strategy produce frequently branched ramets with short spacers and occupy local resources patches in dense populations while plants with the guerrilla strategy produce less frequently branched ramets with longer spacers and grow out of a patch to explore adjacent patches (de Kroon and Knops 1990; de Kroon et al. 1994; Dong and de Kroon 1994). If the function of longer spacer ramets is for expansion, based on the foraging theory, we can expect that sequential production of longer spacer ramets is beneficial for plants to reach new locations with higher possibility. On the other hand, if the function of shorter spacer ramets is for occupation or consolidation, we can expect that the production of limited number of shorter spacer ramets is beneficial to exploit the location with less cost.

Although many studies have been made on the spacer length and branching frequency of ramets, little is known about the sequence pattern of ramets. The differences in the sequence of different types of ramets can change clonal architectures. Figure 1 is an example of two different clonal architectures. Both plants have the same number of Long Rhizome Ramets (LRR) and Short Rhizome Ramets (SRR) (7 and 12 respectively), and branching frequency (3.0 for LRR and no branching for SRR). From spacer length and branching frequency, there are no differences

a)

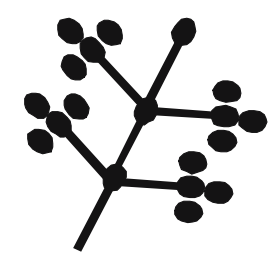

b)

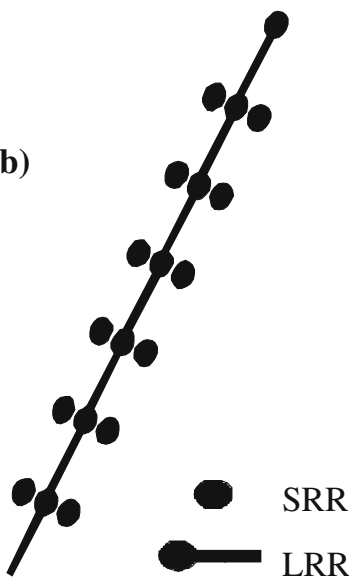

Fig. 1 Schematic drawing of ramet architectures consisting of same number of two types of ramets (Long Rhizome Ramets and Short Rhizome Ramets) with same branching number 
between two plants, but plants in Fig. 1a may have a greater opportunity to exploit the same patch while plants in Fig. 1b may have greater chances of reaching other patches (at least partly). To describe differences in these two architectures, analysing the sequence of ramets is helpful. If every LRR produces a LRR, then plants can spread lineally and reach farther patches like the guerrilla strategy (Fig. 1b), while if only few LRRs produce several LRRs then plants can spread radially and form a clump like the phalanx strategy (Fig. 1a). Thus, the sequences of ramets are as important as the number of branching or the mean length of ramets.

Scirpus olneyi is a clonal species of brackish wetlands that grows and dominates under a rather wide range of environmental conditions, varying from brackish to fresh water sites, and from shady to open habitats (McCormick and Somes 1982; Drake 1984; Ikegami et al. 2006). The ability of $S$. olneyi to successfully colonise a wide range of habitats may be, in part, the result of plasticity in clonal architectures. S. olneyi maintains architectural plasticity by producing two types of ramets, within one clone. Some ramets have very long rhizomes (LRR, Fig. 2a) while others have very short rhizomes (SRR, Fig. 2b). According to the foraging theory of clonal plants, the function of SRRs is expected for occupation while the function of LRRs is expected for expansion or escaping. Thus, we hypothesise that this plant tends to produce SRRs at higher ratio under better environmental conditions to consolidate the patch, while tends to produce LRRs at higher ratio under poor environmental conditions to escape from the patch. This dual clonal strategy enables $S$. olneyi to exploit resources in favourable patches while at the same time exploring the environment for other favourable patches in spatially heterogeneous ecosystems. We also hypothesise that LRRs tend to produce LRRs many times and SRRs tend to produce SRRs for a limited time in a growing season, and LRRs in high quality environments produce both LRRs and SRRs for occupation, while LRRs in low quality environments produce proportionally more LRRs for escaping. To evaluate these hypotheses, we conducted field observations and garden experiments with $S$. olneyi under various conditions.

\section{Plant and communities}

Scirpus olneyi A. Gray, a member of the sedge family Cyperaceae, occurs in different plant communities in tidal wetlands that range from brackish to fresh water along the East Coast of the USA (McCormick and Somes 1982; Drake 1984). The currently accepted scientific name of this species is Schoenoplectus americanus (Pers.) Volk. ex Schinz \& R. Keller. Because $S$. olneyi is still a widely applied name for this species, we have chosen to use it in this study.

The aboveground part of each ramet consists of a vegetative or reproductive shoot that is annual. Shoots are erect, sharply triangular, needlelike, with rudimentary leaves. The belowground parts of a ramet consist of roots, a tuber and a rhizome. The node of each underground ramet is a tuber from which long or short internodes emerge. A daughter tuber with a measurable rhizome is defined as a "Long Rhizome Ramet (LRR)" (Fig. 1a) and a daughter tuber with an unmeasurable rhizome (maximum of a few $\mathrm{mm}$ ) attached to the mother tuber, is defined as a
Fig. 2 Figures of the clonal architecture of Scirpus olneyi. (a) Long Rhizome Ramets (LRRs) and (b) Short Rhizome Ramets (SRRs)

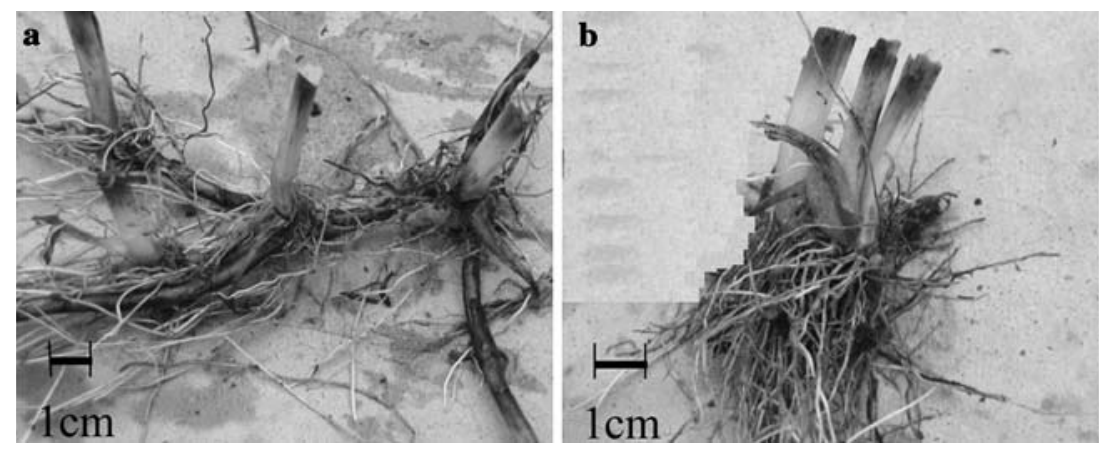


"Short Rhizome Ramet (SRR)" (Fig. 1b). Hereafter in this study, we use the word "a rhizome" for "a tuber with the rhizome".

This research was conducted in three tidal wetlands (locally known as Hog Island Marsh, Corn Island Marsh, and Kirkpatrick Marsh) at the Smithsonian Environmental Research Centre (SERC, 38 $53^{\prime} \mathrm{N}, 76^{\circ} 33^{\prime} \mathrm{W}$ ) in Maryland, USA. $S$. olneyi occurs in several different plant communities at the SERC, and we conducted observations in the four following communities: (1) Scirpus High marsh community (HIGH)

(2) Scirpus Patchy marsh community (PATCHY)

(3) Scirpus Shaded marsh community (SHADED) and (4) Spartina community (SPARTINA) (Ikegami 2004; Ikegami et al. 2006). S. olneyi is a dominant species in the HIGH, PATCHY and SHADED communities, and it invades the SPARTINA community from the edge (McCormick and Somes 1982). The characteristics of each community are as follows (Table 1) (Ikegami 2004):

In the Scirpus High marsh (HIGH) community, light availability drastically declines from the top to the bottom of the canopy due to high shoot densities of $S$. olneyi. Living and partially decomposed shoots, roots and rhizomes of S. patens and/or D. spicata result in a hard, compact substrate. In the Scirpus Patchy marsh (PATCHY) community, hummocks are a characteristic feature. Hummocks are formed by vertical accretion of living and dead shoots of the dominant species. S. olneyi shoot density is high on the hummocks resulting in a steep light gradient from the top of the canopy to the base of the shoots. Light availability is much higher in the open areas between hummocks. Soil compactness varies, since the sediment between hummocks is highly organic and very soft whereas hummock substrates are hard due to the presence of living and dead shoots, rhizomes and roots, primarily of $S$. patens and $S$. olneyi. In the Scirpus Shaded marsh (SHADED) community, species diversity is low and the only common species are $S$. olneyi and Phragmites communis (McCormick and Somes 1982). This community occurs around the edge of the wetland and forms the boundary between the wetland and adjacent upland. Because of overhanging tree branches, light availability in this community is low during the growing season. The substrate consists of highly decomposed organic matter resulting in a very soft substrate. In the Spartina (SPARTINA) community, S. patens is the dominant species and $S$. olneyi appears to invade this community from the margins. Light availability is high for most of the growing season because the shoots of $S$. patens become horizontal shortly after they are mature. The sediment is highly organic and consists of a dense mat of rhizomes and roots of $S$. patens.

\section{Methods}

Field studies

In late November and December 2000, we excavated 25 samples from three different salt marshes (Table 1). The samples were $25 \times 25 \mathrm{~cm}$ and they were excavated to a depth of $20 \mathrm{~cm}$. The samples were washed in the laboratory to remove loose organic material from the ramet systems. Roots and rhizomes were carefully extracted to remove entire ramet systems. We classified every ramet as either a LRR or a SRR and as a current-year ramet or an older-than-one-year ramet (old ramet) and measured the rhizome length (length of a tuber and rhizome). We recorded connections

Table 1 Number of sampled plots in each of the three study sites (Hog Island Marsh, Corn Island Marsh and Kirkpatrick Marsh sites are locally known site names) and the features of each community

\begin{tabular}{lllllllll}
\hline Community & $\begin{array}{l}\text { Total plot } \\
\text { numbers }\end{array}$ & $\begin{array}{l}\text { Hog } \\
\text { Island }\end{array}$ & $\begin{array}{l}\text { Corn } \\
\text { Island }\end{array}$ & Kirkpatrick & $\begin{array}{l}\text { Dominant } \\
\text { species }\end{array}$ & $\begin{array}{l}\text { Light } \\
\text { availability }\end{array}$ & $\begin{array}{l}\text { Soil } \\
\text { compactness }\end{array}$ \\
\hline HIGH & 6 & 2 & 2 & 2 & S. olenyi & Intermediate & Compact & 14 \\
PATCHY & 5 & 2 & 2 & 1 & S. olenyi & Vary & Vary & 13 \\
SHADED & 7 & 3 & 4 & 0 & No dominant & Low & Soft & 11 \\
SPARTINA & 7 & 4 & 0 & 3 & S. patens & High & Compact & 13 \\
\hline
\end{tabular}


between two ramets to describe ramet sequences, thus for each ramet we specified the type and the age of the mother ramet, the existence of daughter ramets, and their types and numbers (branching frequency). The rhizome systems were individually weighed after drying for $72 \mathrm{~h}$ at $68^{\circ} \mathrm{C}$ in a Grieve forced air oven. We excluded ramets that crossed the edge of a plot from length and weight measurements.

In August 2001, we conducted a separate study to compare shoot morphology and biomass allocation patterns in different communities. We excavated ten plots $(10 \times 10 \times 20 \mathrm{~cm})$ in each community; four plots at Hog Island marsh, three plots at Corn Island marsh and three plots at Kirkpatrick marsh. We measured up to four shoots in each plot. For shoot dimensions, we measured shoot height, the width of the broadest side of the triangular shoot at about $10 \mathrm{~cm}$ above the soil surface and the hypotenuse of the "triangle" at that point. We used these data to calculate the Green Area (GA) of the shoots, being the total surface area of the triangular pyramidal shoot. Subsequently, we measured individual shoot weight, total belowground weight of current-year ramets and total belowground weight of old ramets after $72 \mathrm{~h}$ of drying at $68^{\circ} \mathrm{C}$ and calculated the Specific Green Area (SGA), as GA divided by the shoot weight.

\section{Garden experiments}

Growth of $S$. olneyi is primarily influenced by three abiotic factors: nutrients, water (salinity) and light. We conducted three separate experiments to evaluate the effects of nutrients, water salinity, and light on clonal architectures. In May 1999, we obtained 150 genets (seedling) of $S$. olneyi from a plant nursery (PINELANDS NURSERY, NJ, USA). On 1st of June 1999, we chose 75 healthy genets (each genet had 5-7 ramets) and randomly assigned them in equal numbers into the following treatments.

For the nutrient experiment, plants were grown in full sun and fresh water with either $200 \mathrm{~kg}-\mathrm{N} / \mathrm{ha}$ (referred to as Control) or $20 \mathrm{~kg}-\mathrm{N} / \mathrm{ha}$ (referred to as Low-Nutrient) added. The nitrogen source was a commercial slow-release fertiliser (OSMOCOTE). For the salinity experiment, plants were grown in full sun and they were fertilised with $200 \mathrm{~kg}-\mathrm{N} / \mathrm{ha}$. Water salinity was either $10 \%$ (referred to as Low-Salinity) or $20 \%$ (referred to as High-Salinity). For the shading experiment, plants were grown in shade (referred to as Shaded) or full sun (i.e. Control). Standard shade cloth was used to reduce the amount of light to $5 \%$ of full sun. Plants in the Shaded treatment were grown in freshwater and fertilised at a rate of $200 \mathrm{~kg}-\mathrm{N} / \mathrm{ha}$.

In all three experiments, plants were grown in $9 \mathrm{~cm}$ diameter $\times 12 \mathrm{~cm}$ depth plastic pots filled with commercially obtained sand. Water was maintained at the soil surface level by placing five pots into a $25 \times 32 \times 15 \mathrm{~cm}$ tub. Each tub was randomly assigned in the designated area in the garden and changed its location bi-weekly throughout the experiment, except the tubs for the shaded experiment that were kept in two shaded huts $(120 \mathrm{~cm} \times 120 \times 120 \mathrm{~cm})$ in the same garden. Water levels and salinities were monitored regularly and water in every tub was changed simultaneously to maintain the appropriate salinities. On the 24th September, we randomly harvested seven samples from each treatment. After washing sediment from the root systems of each plant, we measured shoot height and quantified clonal architectures by taking the same measurements that were described for the field experiment. Belowground and aboveground biomass measurements were made after $72 \mathrm{~h}$ of drying at $68^{\circ} \mathrm{C}$.

\section{Data analysis}

Fisher's exact test was used to compare the ages of mother ramets that produced new ramets, the number of ramets that produced daughter ramets, and the number of ramets that produced LRRs and/or SRRs. We tested these parameters between SRRs and LRRs within a community and treatment, among LRRs or SRRs in different communities and treatments, between current-year and old LRRs or SRRs in each community. Since Fisher's exact test can be applied to pairs only, for multiple comparisons, we first compared every combination among communities and treatments to calculate $P$-value, and tested for significance by Bonferroni-Dunn post-hoc tests. 
One-way ANOVA was used to compare the mean shoot height, mean SGA values, mean total biomass, mean ratio of aboveground biomass to belowground biomass, mean ratio of current-year belowground biomass to all belowground biomass and mean branching frequency of rhizomes and rhizome length among the four communities and five treatments. We also use one-way ANOVA to compare the mean number of current-year's shoots among four communities in the field and the mean number of ramets among five treatments in the garden experiments. Because of skewed distributions, we used a logarithmic transformation for rhizome length.

\section{Results}

Shoot morphology and biomass allocation

In the HIGH and PATCHY communities, the mean number of current-year's shoots was significantly larger than in the SHADED and SPARTINA communities (Table 2). Average shoot height was tallest in the SHADED community and shortest in the SPARTINA community. SGA (Specific Green Area) value was highest in the SHADED community, but the means were not significantly different from values in the SPARTINA and HIGH communities (Table 2). Plants in the HIGH and PATCHY communities had significantly larger biomass than plants in the SHADED and SPARTINA

Table 2 Mean number of current-year shoots in $10 \mathrm{~cm}^{2}$ plots, mean shoot height $(\mathrm{cm})$, mean SGA (Specific Green Area, $\mathrm{cm}^{2} \mathrm{~g}^{-1}$ ) of shoots, mean total biomass $(\mathrm{g})$, mean

communities (Table 2). The belowground biomass of plants in the HIGH community was twice that of the aboveground biomass. In contrast, plants in the other three communities had more aboveground biomass than belowground biomass (Table 2). Plants in the SHADED community had the highest ratio of aboveground to belowground biomass but the means were not significantly different from the PATCHY and SPARTINA communities (Table 2). Currentyear belowground biomass accounted for only $11 \%$ of all belowground biomass in the $\mathrm{HIGH}$ community, while in the other communities, current-year belowground biomass accounted for more than $60 \%$ of the total belowground biomass (Table 2).

\section{Rhizome morphology}

Figure 3 shows the clonal architectures in four communities. About $80 \%$ of all ramets were SRRs in the PATCHY community while $28 \%$ were SRRs in the SPARTINA community (Table 3). More than about $60 \%$ of current-year LRRs produced new ramets, whereas less than $52 \%$ of SRRs did (Table 3). Current-year LRRs in the SHADED community showed the highest ratio for producing new ramets while this figure was smallest in the PATCHY community, but this was not statistically significant (Table 3). On the other hand, $52 \%$ of current-year SRRs in the PATCHY community produced new ramets while almost $65 \%$ of current-year SRRs did not

ratio of aboveground biomass to belowground biomass and mean ratio of current-year belowground biomass to all belowground biomass (\%)

\begin{tabular}{|c|c|c|c|c|c|c|c|c|c|c|}
\hline Community & $\begin{array}{l}\text { Number of } \\
\text { new shoots }\end{array}$ & & $\begin{array}{l}\text { Shoot height } \\
(\mathrm{cm})\end{array}$ & & $\begin{array}{l}\text { SGA } \\
\left(\mathrm{cm}^{2} / \mathrm{g}\right)\end{array}$ & $\begin{array}{l}\text { Total } \\
\text { biomass (g) }\end{array}$ & & $\begin{array}{l}\text { Ratio of } \\
\text { aboveground } \\
\text { biomass to } \\
\text { belowground } \\
\text { biomass }\end{array}$ & & $\begin{array}{l}\text { Ratio of } \\
\text { current-year } \\
\text { belowground } \\
\text { biomass to all } \\
\text { belowground } \\
\text { biomass }(\%)\end{array}$ \\
\hline $\mathrm{HIGH}$ & $10.4 \pm 3.37$ & $\mathrm{a}$ & $109.35 \pm 12.95$ & $\mathrm{a}$ & $72.67 \pm 18.71 \quad a$ & $34.91 \pm 10.89$ & $\mathrm{a}$ & $0.47 \pm 0.18$ & $\mathrm{a}$ & $11.47 \pm 7.46$ \\
\hline PATCHY & $14.1 \pm 9.12$ & $\mathrm{a}$ & $104.24 \pm 23.55$ & $\mathrm{a}$ & $62.36 \pm 14.42 b$ & $23.86 \pm 6.74$ & $\mathrm{a}$ & $1.92 \pm 0.79$ & $\mathrm{~b}$ & $61.74 \pm 22.88$ \\
\hline SHADED & $3.5 \pm 1.27$ & $\mathrm{~b}$ & $145.92 \pm 30.24$ & $\mathrm{~b}$ & $82.28 \pm 19.46$ ac & $7.53 \pm 2.86$ & $\mathrm{~b}$ & $3.4 \pm 1.40$ & $\mathrm{~b}$ & $71.17 \pm 31.61$ \\
\hline SPARTINA & $3.9 \pm 1.45$ & $\mathrm{~b}$ & $82.43 \pm 15.46$ & $\mathrm{c}$ & $68.02 \pm 13.87 \mathrm{ab}$ & $5.80 \pm 2.43$ & $\mathrm{~b}$ & $1.78 \pm 0.70$ & $\mathrm{~b}$ & $73.24 \pm 26.27$ \\
\hline
\end{tabular}

Values are means $( \pm$ SD). Different letters indicate significant differences between values $(P<0.0083)$ in one-way ANOVA followed by a Bonferroni-Dunn test for multiple comparisons 
Fig. 3 Figures of the clonal architecture of Scirpus olneyi in four different communities. (a) HIGH: Scirpus High Marsh community, (b) PATCHY: Scirpus Patchy Marsh community, (c) SHADED: Scirpus Shaded Marsh community and (d) SPARTINA: Spartina community
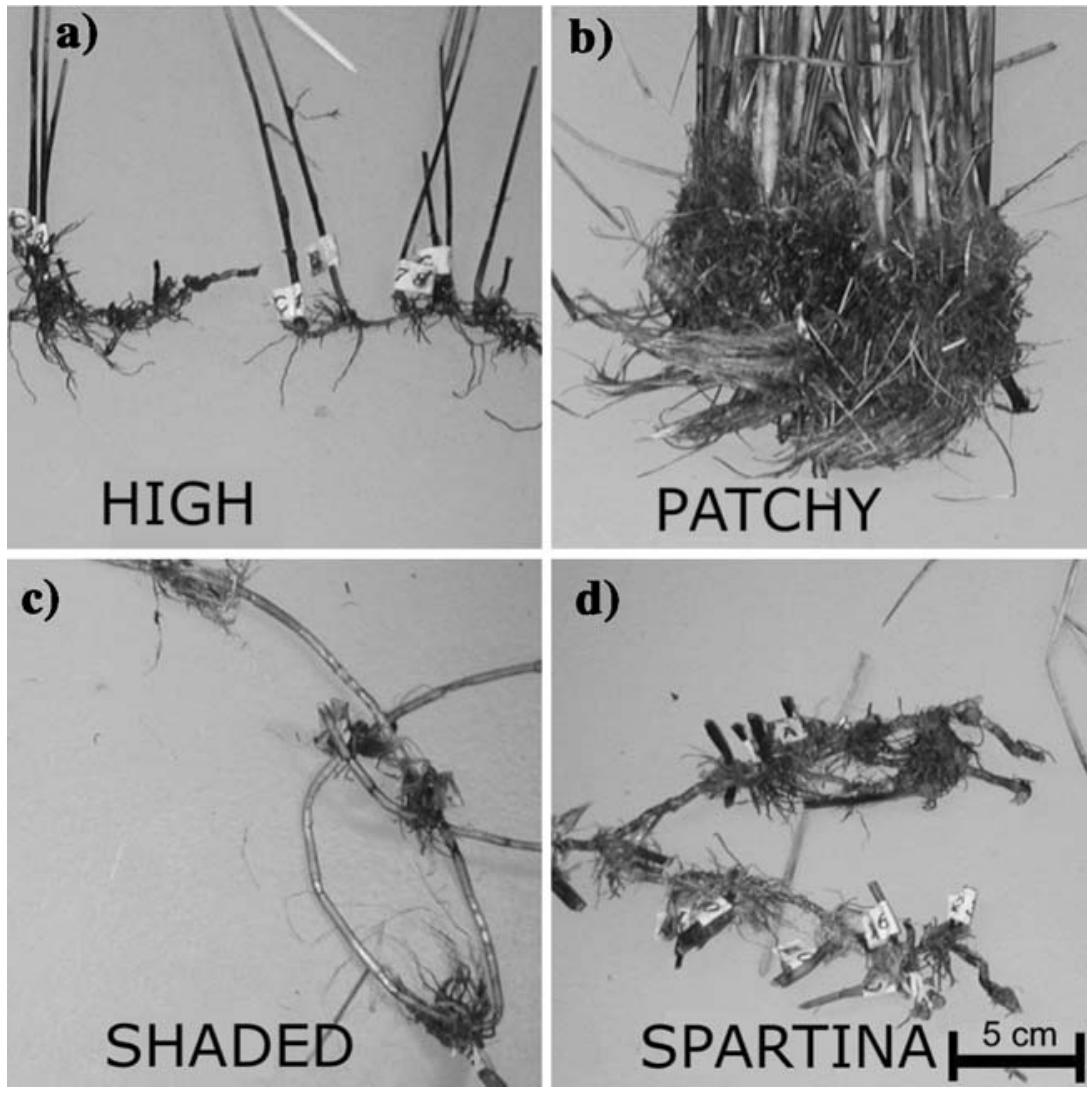

produce any new ramets during the growing season in the SHADED and HIGH communities. More than $85 \%$ of old LRRs produced new ramets during the following growing seasons in the HIGH, PATCHY and SPARTINA communities compared to $70 \%$ in the SHADED community (Table 3). More than $88 \%$ of old SRRs produced new ramets in the following growing seasons in the PATCHY community compared to less than $73 \%$ in other communities. LRRs tended to branch more frequently than SRRs but the differences between the two types of ramets were only significant in the HIGH and PATCHY communities. In the PATCHY community, SRRs and LRRs branched more frequently than ramets in the other three communities (Table 3). Generally, old ramets branch more frequently than current-year ramets, but LRRs in the PATCHY community and SRRs in the SPARTINA community did not show statistical significance. The LRR lengths were greatest in the SHADED community and shortest in the HIGH community and the SRR lengths were shortest in the SHADED community (Table 3 ).

\section{Rhizome connection}

In each community, more than $75 \%$ of currentyear LRRs originated from current-year ramets (Fig. 4). In contrast, 82\% of current-year SRRs originated from current-year ramets in the PATCHY community while only $32 \%$ of current-year SRRs originated from current-year ramets in the HIGH community (Fig. 4). More than $70 \%$ of continued-current-year LRRs (LRRs that keep producing new ramets), produced LRRs in every community, but only $16 \%$ of them produced SRRs in the HIGH and SPARTINA, while this figure was $34 \%$ in the SHADED and $69 \%$ in the PATCHY community (Fig. 5a). More than $90 \%$ of continued-current-year SRRs produced SRRs in the PATCHY community, while $46.7 \%$ in the SPARTINA. Only $14.5 \%$ of continued-currentyear SRRs produced LRRs in the PATCHY 


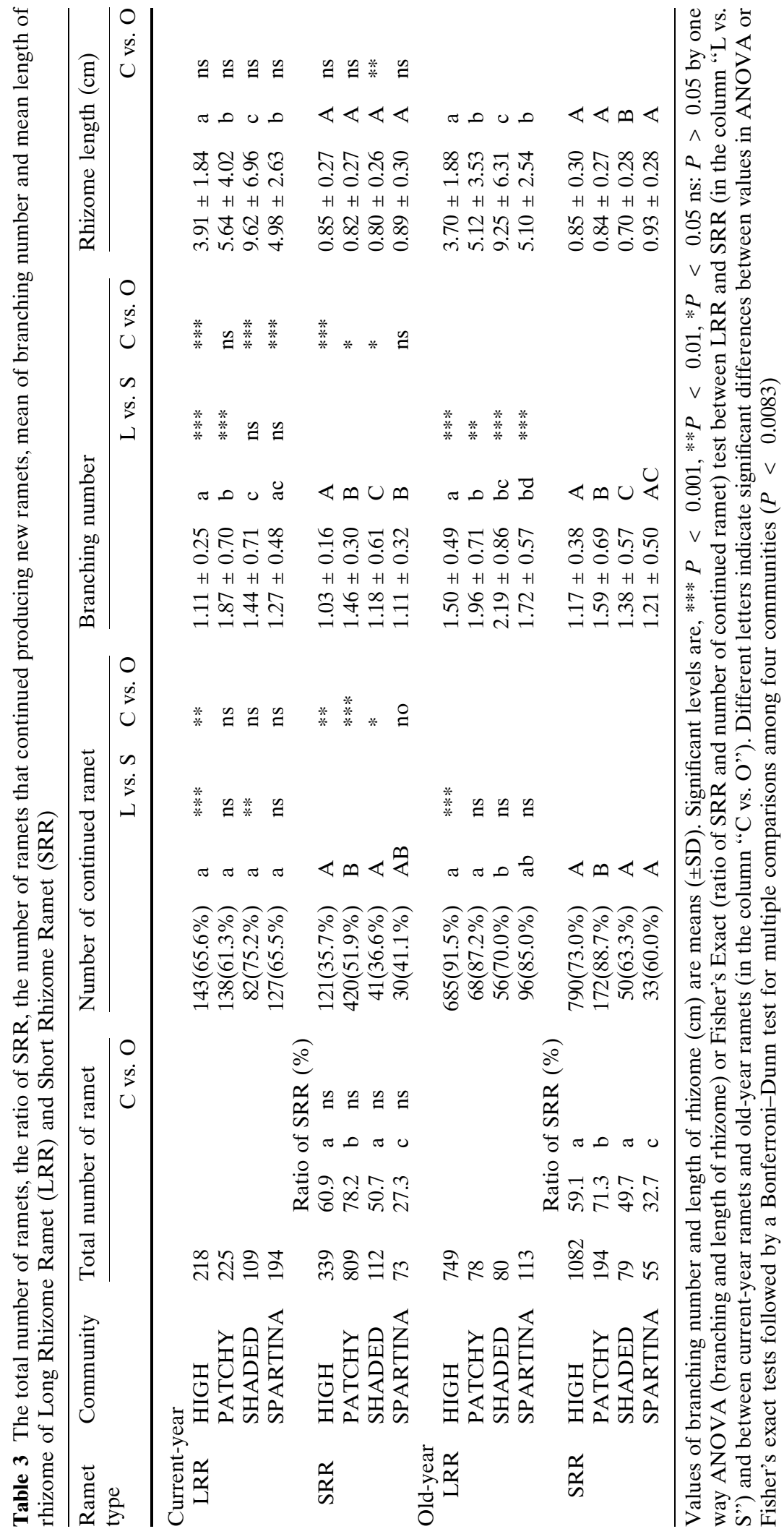




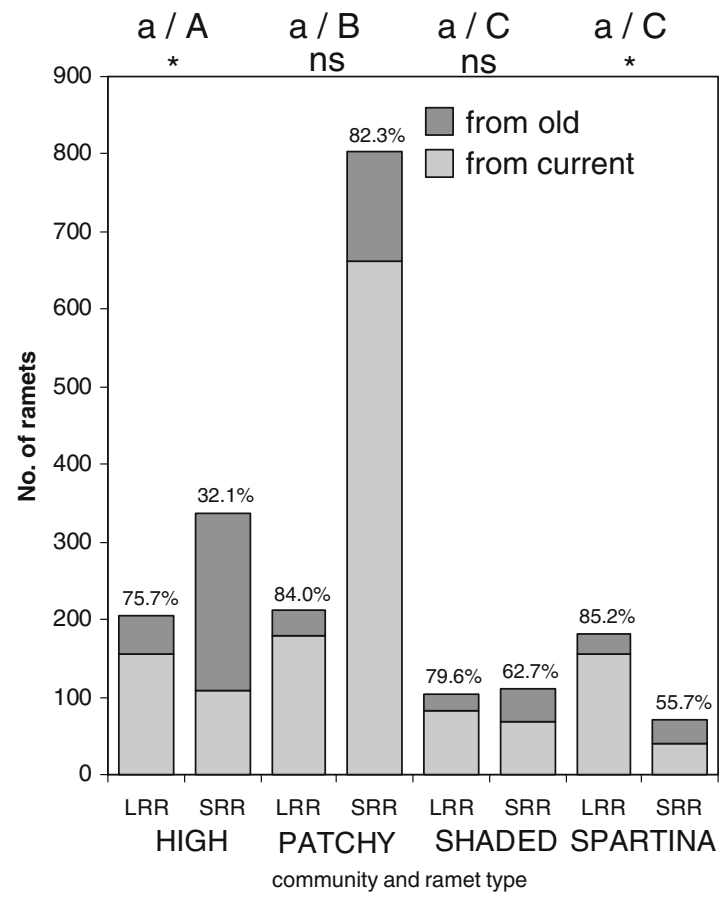

Fig. 4 The total number of current-year LRRs and SRRs originated from current-year ramets or old (older-thanone-year) ramets among four communities. Values above the bars are the proportion of current-year ramets. Symbols above the graph are differences between LRR (lower cases) and SRR (capitals). Significant levels are, *** $P<0.001, * * P<0.01, * P<0.05$, ns: $P>0.05$ tested by Fisher's Exact test. Different letters indicate significant differences between values $(P<0.0083)$ in Fisher's Exact test followed by a Bonferroni-Dunn test for multiple comparisons

community while $56.7 \%$ of SRRs produced LRRs in the SPARTINA community (Fig. 5a). Old ramets showed almost the same pattern as currentyear ramets, but old LRRs tended to produce more SRRs than current-year LRRs in the HIGH and SPARTINA communities (Fig. 5b). In the SHADED community, $64.2 \%$ of old SRRs produced SRRs while more than $82 \%$ of them produced SRRs in the HIGH and PATCHY communities (Fig. 5b).

\section{Results from garden experiments}

The number and biomass of ramets in the Control and Low-Salinity treatments were significantly larger than other treatments (Table 4). Plants in the Shaded treatment had the highest aboveground/belowground biomass ratio in all treat- ments and produced the tallest shoots (Table 4). The SRR ratio was highest in the Low-Salinity treatment and significantly lowest in the LowNutrient treatment (Table 5). More than $75 \%$ of LRRs kept producing new ramets in each experiment (Table 5). On the other hand, there was more variability in the production of SRRs. Less than $50 \%$ of SRRs produced new ramets in the Control and Low-Salinity treatments, while more than $70 \%$ produced new ramets in the LowNutrient treatment (Table 5). Because SRRs in the Control and Low-Salinity treatments branched more frequently, plants in these treatments had more terminal SRRs (Table 5). Among treatments, the number of branches per ramet was significantly different; both LRRs and SRRs in the Control and Low-Salinity treatments branched more frequently than LRRs and SRRs in the Low-Nutrient, High-Salinity and Shaded treatments. LRRs tended to branch more often than SRRs in every treatment, but it was statistically significant in the High-Salinity and LowNutrient treatments only. There were no differences in mean length of LRRs among treatments. SRRs in the Shaded treatments had the longest rhizomes (Table 5).

In the Control and Low-Salinity treatments, LRRs produced the same amount of LRRs and SRRs while LRRs in the Low-Nutrient treatment produced significantly less SRRs (Fig. 6). SRRs in the Low-Salinity treatment produced more SRRs than LRRs, while SRRs in the Shaded and LowNutrient treatments produced more LRRs than SRRs (Fig. 6).

\section{Discussion}

Some clonal plants build a variety of architectural forms by modifying the lengths of spacers (rhizomes or stolons or roots), branching frequencies and branching angles (Hartnett and Bazzaz 1983; Salzman and Parker 1985; Slade and Hutchings 1987a-c). Scirpus olneyi produces two types of ramets, LRRs (Long Rhizome Ramets) and SRRs (Short Rhizome Ramet), and shows variable clonal architectures within the four communities and five treatments examined in this study. Our experiments clearly demonstrated that 


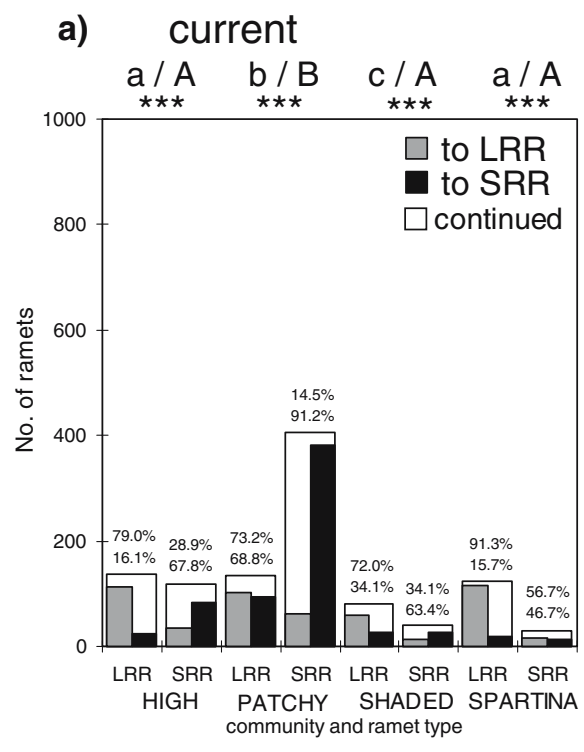

Fig. 5 The number of ramets that produced LRR and/or SRR (a) in current-year ramets and (b) in old ramets, among four communities. Values above the bars are the proportion of daughter ramets that produced LRRs (above) and SRRs (below). Symbols above the bars in (b) are differences between current-year ramets and old ramets and symbols above the graph are differences between LRR and SRR. Significant levels are, $* * * P<0.001, * * P<0.01, * P<0.05$, ns: $P>0.05$ b) old

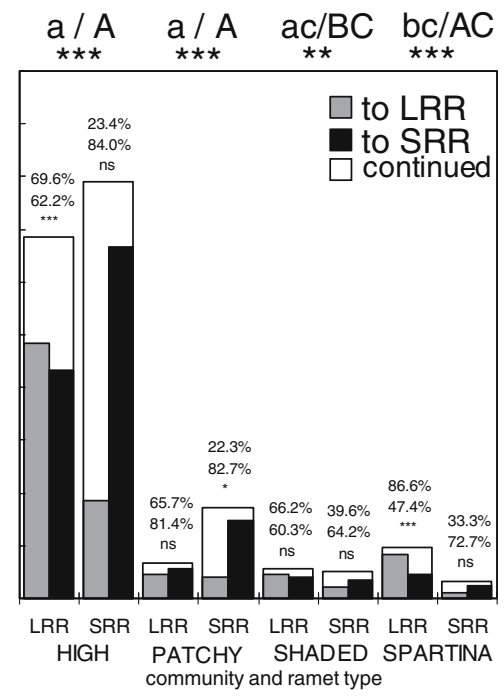

tested by Fisher's Exact test between LRR and SRR or current-year and old ramets. Letters above the graph are differences among four communities; lower cases are differences among LRRs and capitals are differences among SRRs. Different letters indicate significant differences between values $(P<0.0083)$ in Fisher's Exact test followed by a Bonferroni-Dunn test for multiple comparisons

Table 4 Mean number of ramets, mean total biomass (g), mean aboveground/belowground biomass ratio (A/B ratio) and mean shoot height $(\mathrm{cm})$ in the garden experiment $(n=7)$

\begin{tabular}{|c|c|c|c|c|c|c|c|c|}
\hline Treatment & Ramet number & & Total biomass (g) & & $\mathrm{A} / \mathrm{B}$ ratio & & Shoot height $(\mathrm{cm})$ & \\
\hline Control & $44.86 \pm 7.11$ & $\mathrm{a}$ & $9.86 \pm 1.80$ & $\mathrm{a}$ & $0.84 \pm 0.11$ & $\mathrm{a}$ & $53.33 \pm 13.36$ & $\mathrm{a}$ \\
\hline Poor-Nutrient & $27.29 \pm 11.00$ & $\mathrm{~b}$ & $3.55 \pm 1.32$ & $\mathrm{~b}$ & $0.41 \pm 0.02$ & $\mathrm{~b}$ & $34.11 \pm 8.98$ & $\mathrm{~b}$ \\
\hline Low-Salinity & $52.00 \pm 16.61$ & $\mathrm{a}$ & $11.17 \pm 2.86$ & $\mathrm{a}$ & $0.63 \pm 0.10$ & $\mathrm{c}$ & $45.13 \pm 16.15$ & ac \\
\hline High-Salinity & $25.71 \pm 9.38$ & $\mathrm{~b}$ & $2.90 \pm 1.67$ & $\mathrm{~b}$ & $0.44 \pm 0.11$ & bc & $42.24 \pm 11.58$ & bc \\
\hline Shaded & $21.29 \pm 5.88$ & $\mathrm{~b}$ & $2.95 \pm 1.21$ & $\mathrm{~b}$ & $1.07 \pm 0.20$ & $\mathrm{~d}$ & $70.76 \pm 20.33$ & $\mathrm{~d}$ \\
\hline
\end{tabular}

Values are means $( \pm \mathrm{SD})$ and different letters indicate significant differences between values $(P<0.005)$ in one-way ANOVA followed by a Bonferroni-Dunn test for multiple comparisons

S. olneyi changed its clonal architecture with changing branching frequency and the ratio of SRR in response to differences in the habitat quality. In the garden experiments, since every treatment started at the same time, the differences in biomass and the number of ramets among treatments are responses to differing habitat qualities. Results of the garden experiments indicate that biomass and the number of ramets are greatest when plants are growing in high light conditions at intermediate salinities (e.g. 10\%o) while plant performance was lower in higher interstitial salinities, lower light levels and lower nutrient levels (Table 4). Plants growing in better quality treatments also had higher SRR ratios (Table 5). The length of spacers strongly relates to the foraging behaviour of clonal plants. Dong and de Kroon (1994) found that Cynodon dactylon produced shorter rhizomes under higher light conditions. Slade and Hutchings (1987a-c) showed similar results with Glechoma hederacea, and similar results have been shown by others (Lovett Doust 1981; Harper 1985; de Kroon and Knops 1990; Hutchings and de Kroon 1994; Dong 
Table 5 Total ramet number, the ratio of SRR, the number of ramets that continued producing new ramets, mean of branching number per ramet and mean length of ramets

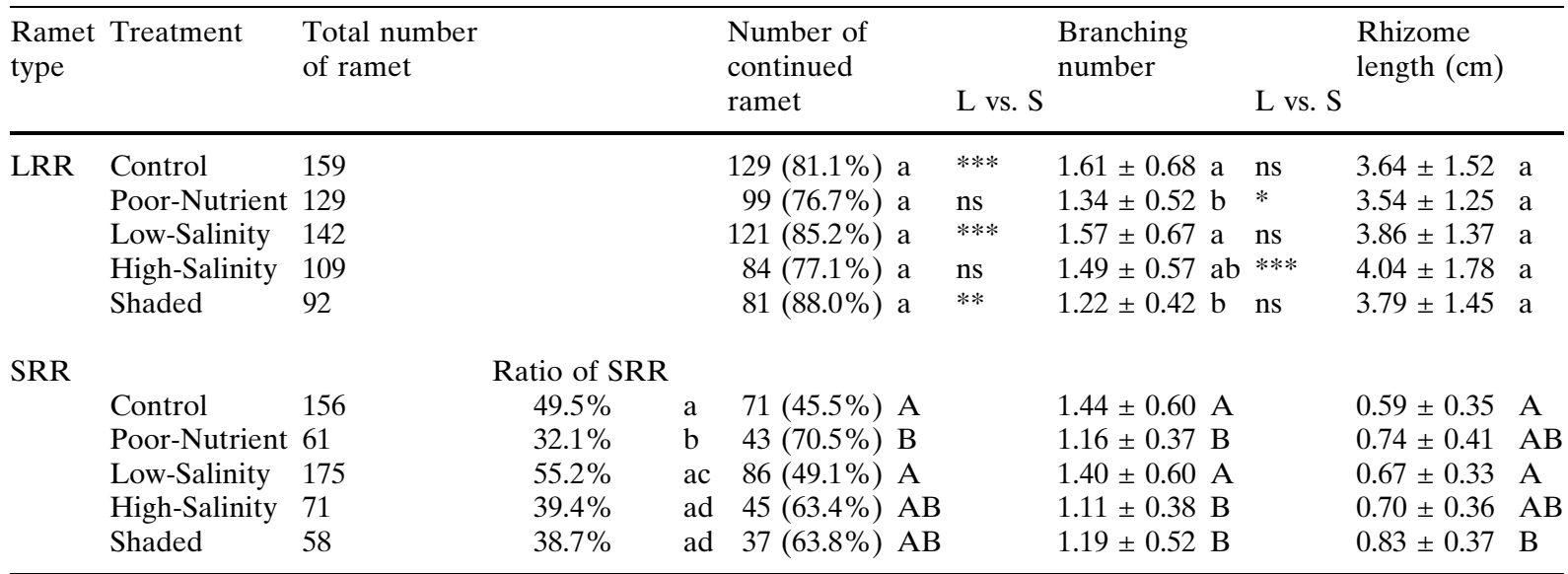

Values are means $( \pm \mathrm{SD})$ for branching number per ramet and length of ramets. Significant levels are, $* * * P<0.001$, $* * P<0.01, * P<0.05$, ns: $P>0.05$ by Fisher's Exact test (ratio of SRR and number of continued ramet) and ANOVA (branching number and length of rhizome) between LRR and SRR. Different letters indicate significant differences between values $(P<0.005)$ in Fisher's exact tests followed by a Bonferroni-Dunn test for multiple comparisons. The characters are differences among habitat, and the symbols in column "L vs. S" are differences between LRR and SRR

1996). De Kroon and Hutchings (1995) summarised the reaction of various clonal plants under different environments (de Kroon and Hutchings 1995). These studies suggest that the production of shorter spacer ramets allows plants to occupy better quality patches while the production of longer spacer ramets allows plants to escape lower quality patches (de Kroon and Knops 1990; Dong and de Kroon 1994; de Kroon and Hutchings 1995). Thus, we conclude that $S$. olneyi produces SRRs as a mechanism to consolidate occupancy and exploit favourable habitats while also having the ability to produce LRRs to explore new and possibly other high-quality habitats.

Our garden experiments showed that plants growing in the high quality treatments had the higher branching frequency of ramets (Table 5). Generally, clonal plants increase the branching frequency of ramets in higher quality patches and decrease in lower quality patches (Slade and Hutchings 1987b,c; Dong 1996) and it is believed that the branching frequency of ramets is more sensitive to environments than the spacer length of ramets (de Kroon and Hutchings 1995). In the experiments, LRRs tended to keep producing new LRRs in every treatment (Table 5, Fig. 6). LRRs in high quality treatments (i.e. Control and
Low-Salinity) also produced SRRs in higher ratio than LRRs in low quality treatments did (i.e. Low-Nutrient, High-Salinity and Shaded) (Table 5, Fig. 6). On the other hand, SRRs tended to stop producing new ramets (Table 5). And if SRRs produced new ramets, a SRR in low quality treatments tended to produce either a LRR or SRR, but proportionally more LRRs while a SRR in high quality treatments (especially in the LowSalinity treatment) produced proportionally more SRRs (Table 5, Fig. 6). Consequently, plants in high quality treatments tend to branch more frequently than plants in low quality treatments and LRRs tend to branch more frequently than SRRs. These results suggest that the function of LRRs is spreading and/or escaping, and once plants reached better environments, then LRRs still produced LRRs but also started producing SRRs to consolidate the patches. And SRRs, originated from LRRs, keep producing SRRs to consolidate patches in high quality treatments while SRRs tended to produce LRRs to continue exploring under low quality treatments (Fig. 6).

In the field, plants showed a variety of growth patterns (Fig. 3). Plants in the HIGH and PATCHY communities had a larger biomass (Table 2) and produced a large amount of seeds (Ikegami 2004; Ikegami et al. 2006). These facts suggested 


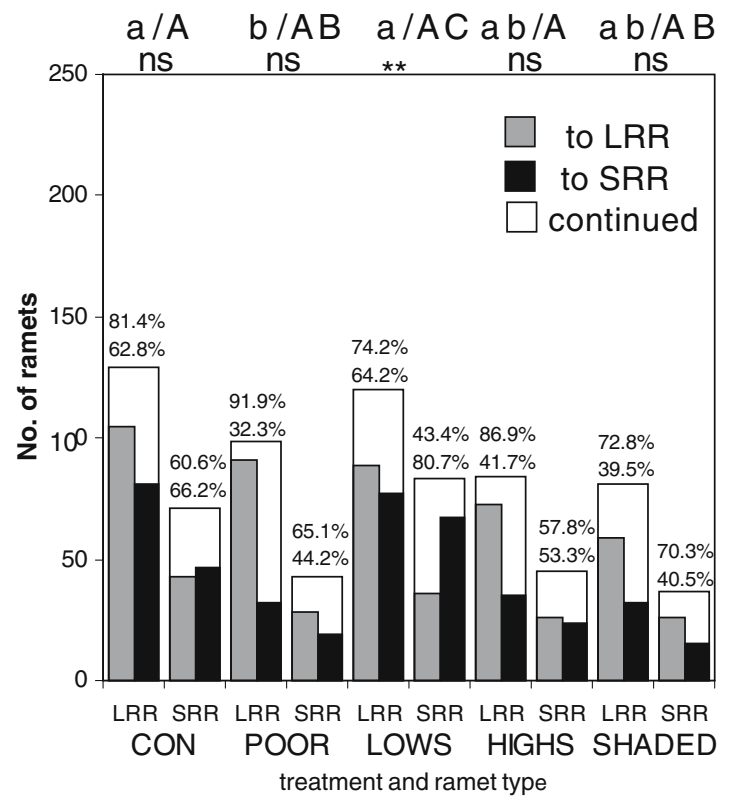

Fig. 6 The number of ramets that produced LRR and/or SRR in daughter ramets. Values above the bars are the proportion of SRR. The symbols above the graph are differences between LRR and SRR. Significant levels are, $* * * P<0.001, * * P<0.01, * P<0.05$, ns: $P>0.05$ tested by Fisher's Exact test between LRR and SRR. The letters above the graph are differences among four communities; lower cases are differences among LRRs and capitals are differences among SRRs. Different letters indicate significant differences between values $(P<0.005)$ in Fisher's Exact test followed by a Bonferroni-Dunn test for multiple comparisons

that plants in these two communities performed better than other communities; thus, these two communities could have better environmental qualities. From foraging theory and our garden experiments, this notion is also supported by the fact that plants in the HIGH and PATCHY communities produced SRRs in higher ratio. Between these two communities, total biomass is larger in the HIGH community but the currentyear's biomass is larger in the PATCHY community (Table 2). Thus, plants in the $\mathrm{HIGH}$ community occupied the same patches for long periods and cumulated large biomass, while plants in the PATCHY community occupied the site for short periods but consolidated patches intensively (by producing many SRRs).

Although both communities showed higher SRR ratio, ramet branching was the lowest in the HIGH community and highest in the PATCHY community among four communities. According to foraging theory and our experiments, however, plants are expected to branch frequently at higher quality patches. From branching frequency, thus, the HIGH community should be lower quality but from the SRR ratio (spacer length), this community should be higher quality. This contradictory result suggests that plants in the HIGH community may have different foraging behaviours. In the HIGH community, because plants occupied the same locality for a longer period, plants are equally distributed and fewer places are available for new ramets. Thus, the intra-ramet competition could be strong in this community (Winn and Pitelka 1981). We assume that plants in the HIGH community avoid intra-ramet competition by producing less branching SRRs (Table 3) fewer times during the same growing season (Fig. 4). This production pattern allows a SRR to occupy the same locality for a longer period. This notion is also supported by the fact that LRRs in the HIGH community did not produce SRRs until the following growing seasons while LRRs in the PATCHY community produced SRRs within the same growing season (Fig. 5a, b).

On the other hand, plants in the SHADED and SPARTINA communities showed lower biomass and lower SRR ratio (Tables 2, 3), and produced almost no seeds (Ikegami 2004; Ikegami et al. 2006). Most of the biomass was in current-year ramets in these communities and ramet branching was intermediate. The SRR ratio in the SHADED and HIGH communities did not have statistical significance, this is because current-year LRRs in the HIGH community produced less SRRs than current-year LRRs in the SHADED community (Fig. 5a). On the other hand, SRRs in the SHADED community produced less SRRs (but more LRRs) than SRRs in the HIGH community, especially in the following year (Table 3, Fig. 5a, b). These results suggest that although plants in SHADED community produced SRRs from LRRs, plants did not (or less) exploit patches by producing SRRs continuously. In the SPARTINA community, LRRs did not produce many SRRs even in the following growing season and it resulted in low SRRs ratio. Thus, we concluded that plants in these two communities were 
exploring new habitats by producing proportionally more LRRs.

The field study and garden experiments show that $S$. olneyi has the plasticity in clonal architecture to consolidate by producing frequently branching ramets with short spacers fewer times (phalanx strategy) or escape/explore in different environments by producing less frequently branched ramets with longer spacers continuously (guerrilla strategy) (Lovett Doust 1981). S. olneyi shows both phalanx and guerrilla strategies within relatively small scale environments; the guerrilla strategy in the SHADED and SPARTINA communities and the phalanx strategy in the PATCHY community (Fig. 2). This plasticity in clonal architecture may allow $S$. olneyi to expand or consolidate patches under various habitats in the field.

Acknowledgements This study was financially supported by a grant to MJAW from the Andrew W. Mellon Foundation through the Smithsonian Institution and by the Faculty of Biology at Utrecht University. We would like to thank Jay O'Neil for his technical help in the fieldwork.

\section{References}

Bell AD (1980) Adaptive architecture in rhizomatous plants. Bot J Linn Soc 80:125-160

Bell AD (1984) Dynamic morphology: a contribution to plant population ecology. In: Dirzo R, Sarukhan J (eds) Perspectives on plant population ecology. Sinauer Associates Incorporated, Sunderland, MA, pp 48-65

de Kroon H, Hutchings MJ (1995) Morphological plasticity in clonal plants: the foraging concept reconsidered. J Ecol 83:143-152

de Kroon H, Knops J (1990) Habitat exploration through morphological plasticity in two chalk grassland perennials. Oikos 59:39-49

de Kroon H, Stuefer JF, Dong M, During HJ (1994) On plastic and non-plastic variation in clonal plant morphology and its ecological significance. Folia Geobot Phytotaxon 29:123-138
Dong M (1996) Clonal growth in plants in relation to resource heterogeneity: foraging behavior. Acta Bot Sin 38:828-835

Dong M, de Kroon H (1994) Plasticity in morphology and biomass allocation in Cynodon dactylon, a grass species forming stolons and rhizomes. Oikos 70:99-106

Drake BG (1984) Light response characteristics of net carbon dioxide exchange in brackish wetland plant communities. Oecologia 63:264-270

Harper JL (1985) Modules, branching, and the capture of resources. In: Jackson JBC, Buss LW, Cook RC (eds) Population biology and evolution of clonal organisms. Yale University Press, New Haven, pp 1-33

Hartnett DC, Bazzaz FA (1983) Physiological integration among intraclonal ramets in Solidago canadensis. Ecology 64:779-788

Hutchings MJ, de Kroon H (1994) Foraging in plants: the role of morphological plasticity in resource acquisition. Adv Ecol Res 25:159-238

Ikegami M (2004) Functional specialization of ramets in a clonal plant network. In Ph.D. Dissertation. Utrecht, Utrecht University, the Netherlands

Ikegami M, Whigham DF Werger MJA (2006) Scirpus olneyi (Cyperaceae) shows phenotypical differentiation in a salt marsh on the east coast of the USA. Polish Botanical Studies in press

Lovett Doust L (1981) Population dynamics and local specialization in a clonal perennial (Ranunculus repens):1. The dynamics of ramets in contrasting habitats. J Ecol 69:743-756

McCormick J, Somes HAJ (1982) The coastal wetlands of Maryland. In Maryland Department of Natural Resources. Baltimore, MD, USA

Salzman AG, Parker MA (1985) Neighbors ameliorate local salinity stress for a rhizomatous plant in a heterogeneous environment. Oecologia 65:273-277

Slade AJ, Hutchings MJ (1987a) Clonal integration and plasticity in foraging behavior in Glechoma hederacea. J Ecol 75:1023-1036

Slade AJ, Hutchings MJ (1987b) The effects of light intensity on foraging in the clonal herb Glechoma hederacea. J Ecol 75:639-650

Slade AJ, Hutchings MJ (1987c) The effects of nutrient availability on foraging in the clonal herb Glechoma hederacea. J Ecol 75:95-112

Winn AA, Pitelka LF (1981) Some effects of density on the reproductive patterns and patch dynamics of Aster acuminatus. Bull Torrey Bot Club 108:438-445 